\title{
Disposition of Quinapril and Quinaprilat in the Isolated Perfused Rat Kidney
}

\author{
Alan R. Kugler, ${ }^{1,2}$ Stephen C. Olson, ${ }^{1}$ and David E. Smith ${ }^{2,3}$ \\ Received April 19, 1995-Final June 25, 1995
}

\begin{abstract}
An isolated perfused rat kidney model was used to probe the renal disposition of quinapril and quinaprilat after separate administration of each drug species. Control studies were performed with drug-free perfusate $(\mathrm{n}=8)$ and perfusate containing quinapril $(\mathrm{n}=9)$ or quinaprilat $(\mathrm{n}=$ 7) at initial drug concentrations of $1000 \mathrm{ng} / \mathrm{ml}$ (including corresponding tracer levels of tritiated drug). Physiologic parameters were within the normal range of values for this technique and were stable for the duration of each experiment. Quinapril and quinaprilat concentrations were determined in perfusate, urine, and perfusate ultrafiltrate using a specific and sensitive reversed-phase $H P L C$ procedure with radiochemical detection, coupled to liquid scintillation spectrometry. Perfusate protein binding was determined using an ultrafiltration method at $37^{\circ} \mathrm{C}$. The total renal clearance of quinapril (CLr) was calculated as Dose/AUC $(0-\infty)$, and is represented by the sum of its urinary and metabolic clearances. The urinary clearances (CLe) of quinapril and quinaprilat were calculated as urinary excretion rate divided by midpoint perfusate concentration for each respective species. Of the total renal clearance for quinapril ( $\mathrm{CLr}=4.49 \mathrm{ml} / \mathrm{min}$ ), less than $0.1 \%$ was cleared as unchanged drug ( $\mathrm{CLe}=0.004 \mathrm{ml} / \mathrm{min})$; over $99 \%$ of the drug was cleared as quinaprilat formed in the kidney. The clearance ratio of quinapril $[\mathrm{CR}=\mathrm{CLr} /(\mathrm{fu} \cdot \mathrm{GFR})]$ was 41.0, a value representing extensive tubular secretion into the renal cells. Following quinaprilat administration, the clearance ratio of metabolite $[\mathrm{CR}=\mathrm{CLe} /(\mathrm{fu} \cdot \mathrm{GFR})]$ was 3.85 , indicating a net secretion process for renal elimination.
\end{abstract}

KEY WORDS: quinapril; quinaprilat; isolated perfused rat kidney; renal disposition; clearance.

\section{INTRODUCTION}

Angiotensin converting enzyme (ACE) inhibitors are a relatively new class of cardiovascular drugs that are gaining wider acceptance as a firstline therapy for hypertension and congestive heart failure $(1,2)$. These drugs

This work was supported in part by a gift from Parke-Davis Pharmaceutical Research, Division of Warner-Lambert Company and by Grant R01 GM35498 from the National Institutes of Health.

'Department of Pharmacokinetics and Drug Metabolism, Parke-Davis Pharmaceutical Research, Division of Warner-Lambert Company, Ann Arbor, Michigan 48106-1047.

${ }^{2}$ College of Pharmacy and Upjohn Center for Clinical Pharmacology, 3705 Upjohn Center, The University of Michigan, Ann Arbor, Michigan 48109-0504.

${ }^{3}$ To whom correspondence should be addressed. 
inhibit the systemic conversion of angiotensin I to the potent vasoconstrictor, angiotensin II, thereby resulting in a lower blood pressure in healthy or hypertensive patients and a higher cardiac output in patients with heart failure (3-6). As antihypertensive agents, ACE inhibitors have also been shown to have significant effects on the kidney, including increases in glomerular filtration rate, renal blood flow, and natriuresis (7). However, the effects of ACE inhibitors on renal hemodynamics may vary widely, depending on the preexisting physiological and pathological state of the kidneys.

Although the acute effects of ACE inhibitors may be directly related to reduced levels of angiotensin II in the plasma, inhibition of tissue ACE may be more important in determining the long-term response to these agents $(5,8)$. This tenet is supported by several lines of experimental evidence. For example, it has been shown that ACE inhibitors are effective in "low renin" hypertensive states even when systemic renin-angiotensin has not been activated. Second, studies in spontaneously hypertensive rats indicate that reductions in blood pressure persisted for weeks after the ACE inhibitor was discontinued and plasma ACE activity returned to normal values; ACE in the vascular wall and kidney, however, remained inhibited. And finally, in addition to the pulmonary vasculature, ACE is present and may have significant pharmacologic activity in other tissues such as blood vessels, brain, heart, kidney, testis, and adrenals. In fact, since all components of the reninangiotensin-aldosterone (RAA) system are also present within the kidney, it is possible that beneficial or undesired effects on renal function may be the result of both the systemic and local RAA systems.

From a drug delivery standpoint, many of the ACE inhibitors have been formulated as prodrugs (e.g., alkyl esters) to improve bioavailability and drug performance. Once these compounds are absorbed, they are deesterified primarily in the liver to their diacid active forms $(4,9,10)$. In this context, enalapril (Vasotec ${ }^{\circledR}$, Merck) is hydrolyzed to enalaprilat and quinapril (Accupril ${ }^{\circledast}$, Parke-Davis) is hydrolyzed to quinaprilat (Fig. 1). Although human plasma esterases are incapable of hydrolyzing these ACE inhibitors $(11,12)$, in vitro rat studies suggest that de-esterification may also occur in other extravascular tissues including the kidney $(13,14)$.

It has been shown that enalapril is extensively converted to its pharmacologically active metabolite enalaprilat ( $90 \%$ conversion) in the isolated perfused rat kidney (15). In a subsequent study using a combined recirculating liver-kidney perfusion model (16), total renal clearance accounted for $30-40 \%$ of all elimination pathways. Thus, it appears that renal clearance can account for a substantial portion of the overall elimination of ACE inhibitor prodrugs, and that intrarenal metabolism is the predominant route of renal clearance in the rat. In addition, enalapril and enalaprilat have been reported to have different renal transport mechanisms; net reabsorption for 
<smiles>COC(=O)[C@H](C[C@@H](C)c1ccccc1)N[C@@H](C)C(=O)N1Cc2ccccc2C[C@H]1C(=O)O</smiles>

${ }^{3}$ H-Quinapril

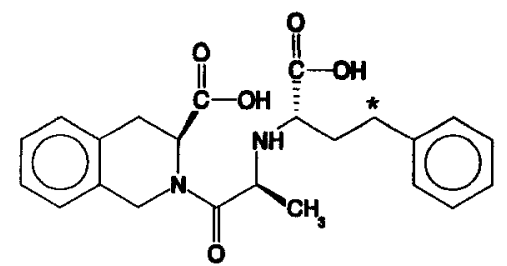

${ }^{3} \mathrm{H}-$ Quinaprilat

Fig. 1. Chemical structures of ${ }^{3} H$-quinapril and ${ }^{3} H$-quinaprilat. The asterisks denote the location of the two tritium atoms in each molecule.

enalapril and net filtration for enalaprilat (15). Still, it should be appreciated that in the presence of renal drug metabolism, a significant portion of the drug may be unaccounted for in the urine. As a result, biotransformation of a drug within the kidney can complicate the interpretation of renal excretion data (17).

Given the delicate relationship of renal drug transport and metabolism, and the apparent dependence of response on tissue dynamics, it is important to elucidate the renal handling of ACE inhibitors. With this in mind, the renal disposition of quinapril and quinaprilat were investigated, using isolated perfused rat kidneys, following the separate administration of each drug species.

\section{MATERIALS AND METHODS}

\section{Perfusion Medium}

The kidney was perfused with a medium containing $6 \%$ bovine serum albumin (BSA, Fraction V; ICN Biomedicals, Irvine, CA) as the oncotic agent. The nutrients used were glucose $(1 \mathrm{~g} / \mathrm{L})$ and a mixture of twenty essential L-amino acids (18) (Sigma Chemical Co., St. Louis, MO) with the following concentrations (mM): Leu (0.40), Phe (0.32), Met (0.33), Lys (1.00), Ile (0.31), Val (0.33), His (0.24), Thr (0.30), Trp (0.07), Ala (1.98), Gly (2.35), Arg (0.51), Pro (0.31), Tyr (0.20), Cys (0.50), Asp (0.20), Glu $(0.50)$, Asn (0.20), Gln (2.00), and Ser (1.00). The BSA and nutrients were dissolved in a modified Krebs-Henseleit bicarbonate buffer (19) with the following component concentrations $(\mathrm{mM}): \mathrm{Na}^{+}(144), \mathrm{K}^{+}(5.04), \mathrm{Ca}^{2+}$ (1.28), $\mathrm{Mg}^{2+}$ (1.19), $\mathrm{Cl}^{-}$(126), $\mathrm{HCO}_{3}^{-}$(24.8), $\mathrm{SO}_{4}^{2-}$ (1.19), $\mathrm{H}_{2} \mathrm{PO}_{4}^{-}(1.19)$. The perfusion medium was prepared in batch, frozen, and stored at $-70^{\circ} \mathrm{C}$. A $200-\mathrm{ml}$ aliquot of perfusion medium was thawed and filtered $(42-\mathrm{mm}$ 
prefilter paired with a $47-\mathrm{mm}, 0.45-\mu \mathrm{m}$ membrane filter; Millipore Corporation, Bedford, MA) at room temperature immediately before use. The perfusion medium was aerated with humidified $\mathrm{O}_{2}: \mathrm{CO}_{2}(95: 5)$ for at least $1 \mathrm{hr}$ before rat kidney arterial cannulation and throughout the duration of the isolated perfused kidney (IPK) experiment. The total apparatus perfusate volume was $100 \mathrm{ml}$ and perfusate $\mathrm{pH}$ was adjusted, if necessary, to 7.4 throughout the experiment. The remaining perfusate was used for volumetric replacement of perfusate samples taken during the study, and for initial cannulation of the renal artery prior to perfusate recirculation.

\section{Animals}

Male Sprague-Dawley rats (328-464 g; Charles River Laboratories, Wilmington, MA) were used as kidney donors for all the IPK experiments. Animals were housed and cared for under the supervision of the University of Michigan's Unit for Laboratory Animal Medicine (ULAM). Animals were acclimated in their new housing for at least 3 days after acquisition and were allowed free access to food and water before experimentation.

\section{Surgical Procedure}

The experimental approach was adopted from those described by Nishiitsutsuji-Uwo et al. (20) and Bowman (21) with minor modifications. Rats were weighed and anesthetized with sodium pentobarbital $(64.8 \mu \mathrm{g} / \mathrm{g}$ body weight, intraperitoneal). After induction of deep anesthesia (approximately $15 \mathrm{~min}$ ), the rats were transferred to a surgical tray and secured in a supine position. The left superficial femoral vein was exposed and was used to administer a bolus of mannitol $(180 \mathrm{mg} ; 10 \%$ normal saline solution) and heparin $(200 \mathrm{U} ; 1000 \mathrm{U} / \mathrm{ml}$ solution $)$.

A midline incision was then made, the viscera gently positioned to one side, and the major abodminal blood vessels were isolated. The right ureter was catheterized with $10 \mathrm{~cm}$ of PE-10 polyethylene tubing (leading edge cut at a $45^{\circ}$ angle to facilitate insertion, $0.28 \mathrm{~mm}$ i.d., $0.61 \mathrm{~mm}$ o.d.; Clay Adams, Parsippany, NJ) and secured with three ligatures. Distal and proximal ligatures were placed around the superior mesenteric artery, and a single ligature was set around the right renal artery. The distal mesenteric ligature was tied and a serrefine (Diethrich, 2-inch with 8-mm serrated jaws, $50 \mathrm{~g}$ pressure; Biomedical Research Instruments, Inc., Rockville, MD) was placed on the mesenteric artery close to the aorta. A small cut was made in the mesenteric artery and a 19-gauge stainless stell cannula (hypodermic needle cut to 1.5inch long, bent at a right angle 0.5 inch from the tip which was rounded; Pepper and Sons, New Hyde Park, NY) was inserted distally into the mesenteric artery up to the depth of the serrefine. The serrefine was removed, and 
the cannula was manipulated across the aorta and into the right renal artery. Perfusion flow was initiated as soon as the cannula entered the renal artery, thereby minimizing interruption of flow to the kidney. After the proximal mesenteric and renal artery ligatures were secured, the kidney was rapidly excised from the animal and carefully trimmed of adhering tissue.

Approximately $20 \mathrm{ml}$ of perfusate were allowed to pass through the kidney to remove any residual blood before recirculation was started. The kidney surface was also cleansed with normal saline during this prerecirculation period. The kidney was transferred to the perfusion apparatus which was completely enclosed within a Plexiglas ${ }^{\mathrm{TM}}$ chamber maintained at $37^{\circ} \mathrm{C}$. Perfusion pressure at the tip of the renal cannula was kept at about $80 \mathrm{~mm} \mathrm{Hg}$ (corrected for intrinsic apparatus pressure) by monitoring the manometer and adjusting the flow-restriction valve accordingly. Surgery was normally completed within $10-15 \mathrm{~min}$.

\section{Perfusion Apparatus}

A schematic of the recirculating IPK apparatus is illustrated in Fig. 2. Perfusion medium was pumped from the perfusate reservoir by a peristaltic roller pump (Model 502-S170; Watson-Marlow, Inc., Marblehead, MA), passed through a system of four parallel filters (22-mm prefilter paired with a 25-mm, 8- $\mu \mathrm{m}$ membrane filter; Millipore Corporation, Bedford, MA), and on to an oxygenator. The multibulb oxygenator assured complete spread of the perfusion medium over its surface. The $\mathrm{O}_{2}: \mathrm{CO}_{2}$ mixture, bubbled

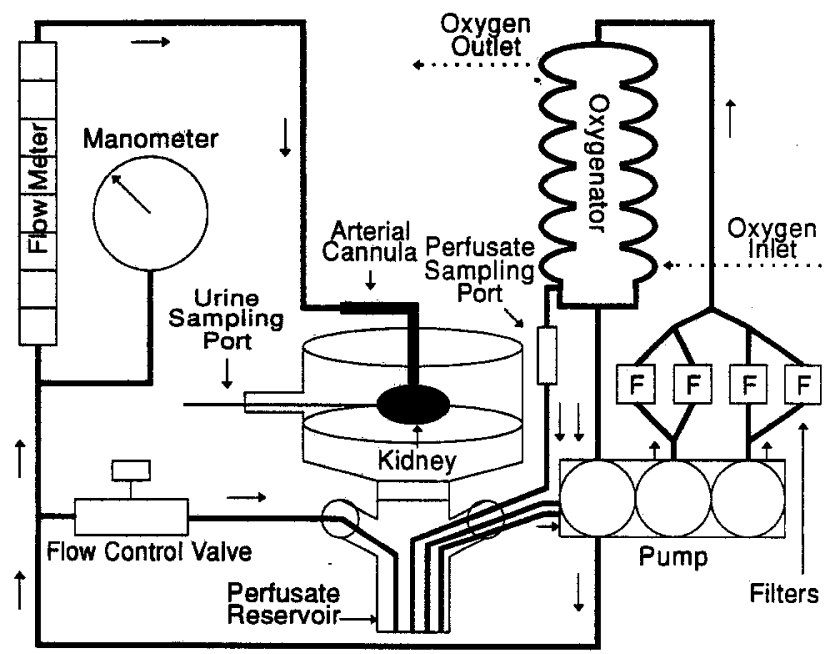

Fig. 2. Illustration of the recirculating isolated perfused rat kidney apparatus. 
through a gas-washing bottle containing water, entered at the bottom of the oxygenator $(6 \mathrm{~L} / \mathrm{min})$ and the excess gas passed through an outlet at the top of the oxygenator. The perfusate then passed through the pump again and its flow was divided by a two-way tubing connector to a flowmeter (Type R-2-15-A with Size 2 Tantalum Float; Thomas Company, Philadelphia, PA) and through a flow-restriction valve (Whitey, Cleveland, $\mathrm{OH})$ which emptied into the reservoir. This valve was adjusted so that different flow rates and associated pressures could be attained. The flow and pressure were monitored continuously, using the flowmeter and a manometer (sphygmomanometer, pocket aneroid type; Tycos Instruments, Inc., Arden, $\mathrm{NC}$ ), and values were recorded every 10 min during each experiment coinciding with perfusate sampling. The manometer was protected from direct contact with the perfusate by an in-liner filter (Acrodisc ${ }^{\circledR}$ CR PTFE, 0.45$\mu \mathrm{m}, 25-\mathrm{mm}$ diameter; Gelman Sciences, Ann Arbor, MI).

A kidney tray, fashioned by tightly stretching a nylon mesh over a 7.5$\mathrm{cm}$ diam sheet metal ring, prevented loose tissue from entering the reservoir. A horizontal limb, mounted $2.5 \mathrm{~cm}$ above the tray, supported the cannulated kidney. The tray was positioned in the top half of a glass funnel $(13-\mathrm{cm}$ height $\times 8.5-\mathrm{cm}$ diam) designed to conduct perfusate back to the reservoir. The perfusate sampling port (flashback from a Venoset ${ }^{\circledR}$ Microdrip ${ }^{\oplus}$; Abbott Laboratories, North Chicago, IL) was located at the bottom of the oxygenator where excess perfusate could reenter the reservoir. Urine was collected via a ureter catheter placed through a side-arm of the glass funnel.

\section{Quinapril and Quinaprilat}

${ }^{3} \mathrm{H}$-Quinapril and ${ }^{3} \mathrm{H}$-quinaprilat were obtained from Amersham Buchler GmbH \& Co. KG, Braunschweig, Germany. Radiochemical purity of both compounds was determined to be $>98 \%$ by HPLC. Specific activities were 8.80 and $9.10 \mathrm{Ci} / \mathrm{mmol}$ for ${ }^{3} H$-quinapril and ${ }^{3} H$-quinaprilat, respectively. Unlabeled quinapril (hydrochloride) and quinaprilat (monohydrate) were obtained from Parke-Davis, Ann Arbor, MI. Purity of both compounds was determined to be $\geq 99 \%$ by HPLC. For the IPK studies, $0.200 \mathrm{ml}$ of ${ }^{3} \mathrm{H}$-quinapril stock solution $(47.9 \mu \mathrm{g} / \mathrm{ml}$ in acetonitrile: $0.05 \mathrm{M}$ potassium phosphate) was combined with $0.904 \mathrm{ml}$ of unlabeled quinapril $(10 \mathrm{mg}$ dissolved to $100 \mathrm{ml}$ with water), evaporated under a gentle stream of nitrogen, and rapidly reconstituted with $1 \mathrm{ml}$ of blank perfusate to give a total quinapril dose of $100 \mu \mathrm{g}$. For IPK studies with quinaprilat, a $0.150 \mathrm{ml}$ aliquot of ${ }^{3} H$-quinaprilat stock solution $(43.4 \mu \mathrm{g} / \mathrm{ml}$ in acetonitrile $: 0.05 \mathrm{M}$ potassium phosphate) was combined with $0.935 \mathrm{ml}$ of unlabeled quinaprilat $(10 \mathrm{mg}$ dissolved in $5 \mathrm{ml}$ methanol and diluted to $100 \mathrm{ml}$ with water), evaporated under a gentle stream of nitrogen, and rapidly reconstituted with $1 \mathrm{ml}$ of blank perfusion medium to give a total quinaprilat dose of $100 \mu \mathrm{g}$. 


\section{Experimental Protocol}

Following a 15 -min period for equilibration, ${ }^{14} C$-inulin $(0.150 \mathrm{ml}$ of a $16.7 \mu \mathrm{Ci} / \mathrm{ml}$ solution, specific activity $2.5 \mu \mathrm{Ci} / \mathrm{mg}$; ICN Biomedicals Inc., Irvine, CA) and ACE inhibitor $\left({ }^{3} \mathrm{H}\right.$-quinapril or ${ }^{3} \mathrm{H}$-quinaprilat) were introduced as a bolus to the recirculating perfusion medium. An additional $15 \mathrm{~min}$ were allowed for drug distribution and hemodynamic stability to occur. The remaining $90 \mathrm{~min}$ of perfusion time were divided into 10 -min urine collection intervals for the evaluation of physiologic and urinary clearance parameters. Urine was collected into, and its volume measured with, a 1-cc tuberculin syringe. Perfusate $(1.5 \mathrm{ml})$ was withdrawn with a 3 -cc syringe (21-gauge needle) at the midpoint of each clearance interval. Additional urine $(0$ $15 \mathrm{~min}$ ) and perfusate $(10 \mathrm{~min})$ samples were collected during the 0 15 minute postbolus equilibration period. These additional samples were used for quinapril and quinaprilat pharmacokinetic calculations only, in which $0-t$ or $0-\infty$ time data were required (e.g., $A e, A U C$ ). Changes in perfusate composition due to the collection of urine and perfusate samples were minimized by isovolumetric replacement with modified KrebsHenseleit buffer and blank perfusion medium (no inulin present), respectively. Perfusate and urine $\mathrm{pH}$ were determined immediately after collection (Model $\Phi^{\mathrm{TM}}-61, \mathrm{pHI}^{\mathrm{TM}}$; Beckman Instruments, Inc., Irvine, CA). A schematic representation of the experimental time schedule is presented in Fig. 3.

Nine experiments were conducted to define the disposition of quinapril and quinaprilat in the IPK after administration of quinapril, and seven experiments were conducted to define the disposition of quinaprilat in the

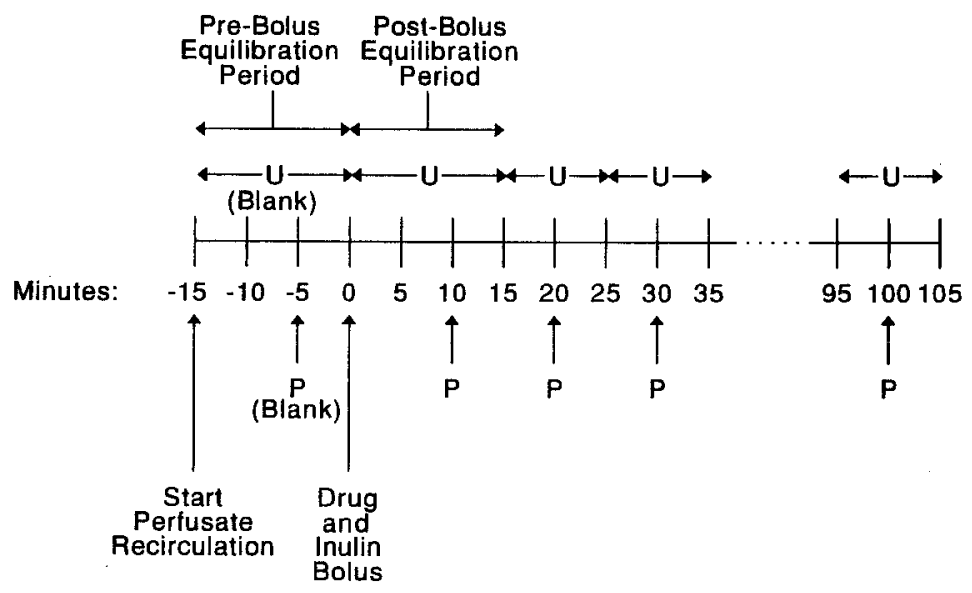

Fig. 3. Schematic representation of the experimental time schedule for IPK studies with quinapril and quinaprilat. 
IPK after administration of quinaprilat. The initial perfusate concentrations of quinapril and quinaprilat were $1000 \mathrm{ng} / \mathrm{ml}$ following their respective doses. Eight control studies (no ACE inhibitor present) were also performed to establish baseline physiology and viability of the IPK model.

\section{Analytical}

${ }^{14} \mathrm{C}$-Inulin concentrations were determined in perfusate and urine samples by dual label spectrometry. Briefly, a $100-\mu 1$ aliquot of perfusate or urine was combined with $15 \mathrm{ml}$ of scintillation cocktail (Ready Safe ${ }^{\mathrm{TM}}$; Beckman Instruments Inc., Fullerton, CA) in $20-\mathrm{ml}$ glass scintillation vials. Samples were mixed thoroughly, allowed to settle in the dark for $24 \mathrm{hr}$, and each counted for $20 \mathrm{~min}$ or until a $1 \%-2 \sigma$ error was reached by liquid scintillation spectrometry (LS 7500; Beckman Instruments Inc., Arlington Heights, IL). Values of counts per minute (cpm) and quench were converted to disintegrations per minute (dpm) using an established ${ }^{3} \mathrm{H} /{ }^{14} \mathrm{C}$ dual-label quench curve.

Perfusate and urine glucose concentrations were determined by a method employing an immobilized glucose oxidase membrane coupled to an electrochemical sensor (Model 27; Yellow Springs Instruments, Yellow Springs, $\mathrm{OH})$. The procedure required a sample volume of $25 \mu 1$ and concentration was reported by the instrument in units of $\mathrm{mg} / \mathrm{dl}$. The instrument was zeroed between each sample against a buffer background and calibrated frequently with a $100 \mathrm{mg} / \mathrm{dl}$ glucose reference solution. Replicate measurements $(n=16)$ of the glucose reference solution gave a mean bias within $\pm 2 \%$ and a coefficient of variation of less than $2 \%$.

Sodium concentrations were determined in perfusate and urine samples by flame photometry (Model 480; Ciba-Corning Diagnostics Corp., Medfield, MA). Approximately $75 \mu 1$ of sample was used by the instrument for each determination and concentration was reported by the instrument in units of $\mathrm{mmol} / \mathrm{L}$. The sample was combined with an internal standard solution to compensate for fluctuations in the flame and diluted automatically with deionized water prior to excitation. Replicate measurements $(n=16)$ of the sodium reference solution gave a mean bias within $\pm 2 \%$ and a coefficient of variation of less than $2 \%$.

Quinapril and quinaprilat concentrations were determined in perfusate, urine, and perfusate ultrafiltrate using a specific and sensitive reversed-phase HPLC procedure with radiochemical detection, coupled to liquid scintillation spectrometry (22). Briefly, cpm values were converted to $\mathrm{dpm}$ values using an established ${ }^{3} \mathrm{H} /{ }^{14} \mathrm{C}$ dual-label quench curve. Liquid scintillation counting data (dpm) were multiplied by fractional chromatographic areas (drug ${ }^{3} \mathrm{H}$-peak area/total ${ }^{3} \mathrm{H}$-peak area) and total drug amounts were then calculated using the corresponding specific activities. 


\section{Protein Binding}

The binding of quinapril and quinaprilat to perfusate albumin was determined by ultrafiltration. Binding experiments were performed using a disposable micropartition device (Centrifree ${ }^{\circledR}$; Amicon Div., W. R. Grace \& Co., Danvers, MA). The device employs an anisotropic, hydrophilic YMT membrane that excludes molecules larger than approximately $30 \mathrm{kdal}$. A 0.6- $\mathrm{ml}$ aliquot of perfusate was introduced to the device, capped, equilibrated at $37^{\circ} \mathrm{C}$ for $15 \mathrm{~min}$ in a fixed $35^{\circ}$ angle rotor, and then centrifuged (IEHHN II; Damon/IEC Division, Needham Heights, MA) at $1800 \mathrm{~g}$ for $20 \mathrm{~min}$ at $37^{\circ} \mathrm{C}$. When necessary, perfusate $\mathrm{pH}$ was adjusted to 7.4 by gassing the sample with $\mathrm{CO}_{2}$ or by vortexing the sample to remove excess $\mathrm{CO}_{2}$. Approximately $350 \mu \mathrm{l}$ of protein-free ultrafiltrate were harvested from each sample.

\section{Stability of Quinapril in Isolated Perfused Kidney}

The stability of quinapril was determined in recirculated perfusate and generated urine from IPK experiments. These experiments were similar to IPK studies described previously (but with no inulin or drug present), and were performed to determine if extracellular metabolism of quinapril occurs in the IPK model. Thus, isolated rat kidneys were perfused $(n=3)$ and the perfusate sampled at 40,80 , and $120 \mathrm{~min}$ and urine collected over intervals of $0-40,40-80$, and $80-120 \mathrm{~min}$. These samples were then used to incubate spiked quinapril at concentrations of 10 and $1000 \mathrm{ng} / \mathrm{ml}$ at $37^{\circ} \mathrm{C}$. The spiked samples were incubated for 40,80 , and $120 \mathrm{~min}$, quenched with acetonitrile, and then assayed for quinapril and and quinaprilat by HPLC procedure described previously.

\section{Data Analysis}

The renal clearances of inulin, glucose, and sodium were determined by dividing the urinary excretion rate of each substance by its respective perfusate concentration at the midpoint time interval. The fractional urinary clearances of glucose ( $F E$ glucose) and sodium ( $F E$ sodium) were calculated as the renal clearance of each species divided by glomerular filtration rate $(G F R)$. The renal clearance of inulin was taken to represent $G F R$.

In IPK studies with quinapril, the total renal clearance of drug is represented by the sum of its urinary and metabolic clearances (i.e., $C L r=$ $C L e+C L m$ ). Thus, quinapril's total renal clearance $(C L r)$ can be determined experimentally as

$$
C L r=\frac{\text { Dose }}{A U C(0-\infty)}
$$


where $A U C(0-\infty)$ is the area under the perfusate drug concentration-time curve from time zero to infinity. $A U C(0-\infty)$ values were determined using the log-trapezoidal rule for experimental data, and extrapolated to infinity using Cplast $/ \lambda z$. The extrapolated area was about $2 \%$ of the total $A U C$ for IPK studies with quinapril. The log-linear terminal half-life $\left(T_{1 / 2}\right)$ of quinapril was calculated as $\ln (2) / \lambda z$; the rate constant $(\lambda z)$ was estimated from the slope of a least-squares linear regression of the natural logarithm perfusate drug concentration-time profile during the terminal phase. The total renal clearance of quinapril was normalized for the fraction unbound $(f u)$ and renal function (i.e., $G F R$ ) through calculation of its clearance ratio ( $C R$; determined using the total renal clearance method).

$$
C R=\frac{C L r}{f u \cdot G F R}
$$

The urinary clearance of quinapril was calculated for each urinary collection period as

$$
C L e=\frac{U \cdot V}{C p m i d}
$$

where $U$ is the concentration of quinapril in urine, Cpmid is its midpoint perfusate concentration, and $V$ is the urinary flow rate. And finally, the metabolic clearance of quinapril $(\mathrm{CLm})$ was calculated as

$$
C L m=C L r-C L e
$$

In IPK studies with quinaprilat (after administration of quinapril or quinaprilat), the urinary clearance of quinaprilat (CLe) was calculated in an analogous manner to that of quinapril, using Eq. (3). The urinary clearance of quinaprilat was then normalized for the fraction unbound $(f u)$ and renal function (i.e., $G F R)$ through calculation of its clearance ratio $(C R$; determined using the urinary clearance method)

$$
C R=\frac{C L e}{f u \cdot G F R}
$$

Due to quinaprilat's slow rate of decay from the perfusate, $T_{1 / 2}$ and $A U C(0-$ $\infty)$ estimates for quinaprilat were not reported. For the same reason, quinaprilat's renal clearance is more accurately determined when dividing its urinary excretion rate by the corresponding midpoint perfusate concentration.

For both quinapril and quinaprilat studies, the cumulative amount of drug excreted in the urine from Time 0 to $105 \mathrm{~min}[\mathrm{Ae}(0-105)]$ was also determined, and is expressed as percentage of the administered dose. The 
free fraction $(f u)$ of drug in the perfusate, expressed as a percentage, was calculated as

$$
f u(\%)=\frac{\text { Perfusate Ultrafiltrate Drug Concentration }}{\text { Perfusate Drug Concentration }} \cdot 100 \%
$$

Data are reported as the mean $\pm \mathrm{SD}$, unless otherwise indicated. To test for statistically significant parameter differences among groups, one-way analysis of variance (ANOVA) was performed. When the $F$ ratio showed that there were significant differences among groups, the Student-NewmanKeuls method of multiple comparisons was used to determine which groups differ. All statistical tests employed an $\alpha=.05$ significance level. Means that were not significantly different were reported with the same capital letter in tables. All statistical computations were done using SAS 5.18 software (SAS Institute; Cary, NC).

\section{RESULTS}

\section{Physiologic Parameters}

Perfusion pressure, perfusate flow rate, GFR, FEglucose, FEsodium, urine flow rate, and urine $\mathrm{pH}$ were evaluated as indices of renal functionality in control, quinapril and quinaprilat IPK studies (Table I). Although renal function was similar between the drug and control groups, some minor differences did exist. GFR was $25 \%$ greater in quinapril vs. control, urine flow rate was $37-58 \%$ larger in drug vs. control, and urine $\mathrm{pH}$ was increased in quinapril vs. control studies. There were no significant differences in IPK function when comparing quinapril vs. quinaprilat administration with one exception; GFR differed by about $20 \%$ in these studies. Overall, physiologic parameters were within the normal range of values for this technique (2328 ), and were stable for the duration of each experiment.

\section{Stability of Quinapril in Isolated Perfused Kidney}

In these preliminary experiments, quinapril degradation was not observed under any of the conditions studied. These results demonstrate that the kidney is not releasing enzymes that can de-esterify quinapril in the recirculating perfusate or generated urine over the course of the IPK experiments. Therefore, in the IPK model any esterolysis of quinapril can be attributed to cellular kidney metabolism. Similar results were also observed for enalapril in the isolated red blood cell-perfused rat kidney (15). 


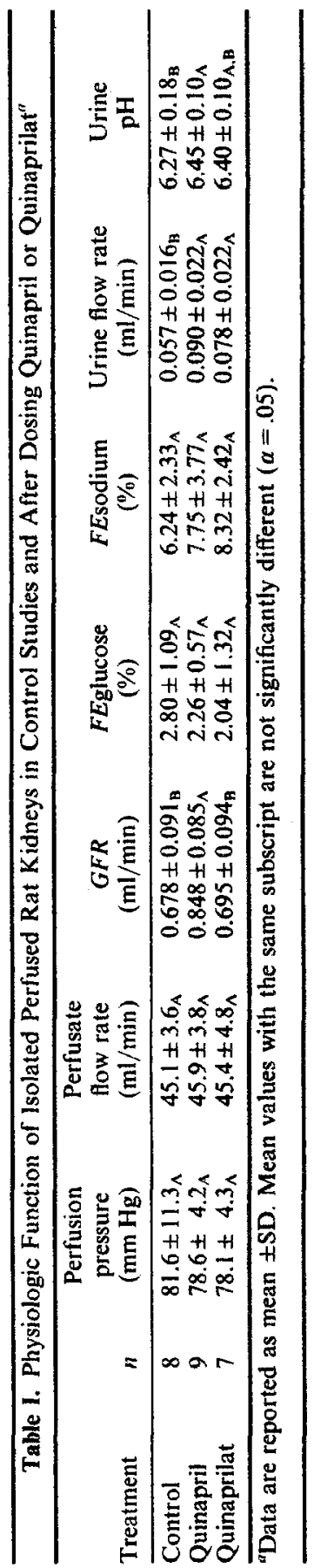




\section{Drug Studies}

When quinapril was administered to the IPK, perfusate concentrations of parent drug declined rapidly with a $T_{1 / 2}$ of $16.5 \pm 1.5 \mathrm{~min}$ (Fig. 4). Quinaprilat was formed rapidly and extensively (from quinapril) within the kidney and tended to accumulate with time. When metabolite was administered, quinaprilat was eliminated slowly from the perfusate, and intrarenally formed and preformed quinaprilat levels appear indistinguishable $\geq 60 \mathrm{~min}$ postdose. Thus, once quinapril was largely removed from the perfusate, the kidney handled quinaprilat in a similar fashion regardless of its source.

After quinapril administration (Table II), the clearance ratio of parent drug was 41.0 [using the total renal clearance method of Eq. (2)], indicating that quinapril undergoes an extensive tubular secretion into the renal epithelial cells. Of the total renal clearance $(C L r=4.49 \mathrm{ml} / \mathrm{min})$, less than $0.1 \%$ of quinapril was cleared as unchanged drug $(C L e=0.004 \mathrm{ml} / \mathrm{min})$; over $99 \%$ of the drug was cleared as metabolite formed in the kidney $(C L m=4.48 \mathrm{ml} /$ $\mathrm{min}$ ). Metabolic clearance reflects that of quinaprilat since no other metabolites were formed in the kidney. The fraction unbound was $13 \%$ for quinapril, and protein binding was linear over the drug concentrations studied.

Following quinaprilat administration (Table II), the clearance ratio of metabolite was 3.85 [using the urinary clearance method of Eq. (5)], which indicates a net secretion process for its renal elimination. In addition, the clearance ratio of quinaprilat after quinapril administration was 4.73 , a value that was variable as a function of time (Fig. 5). Nevertheless, the clearance

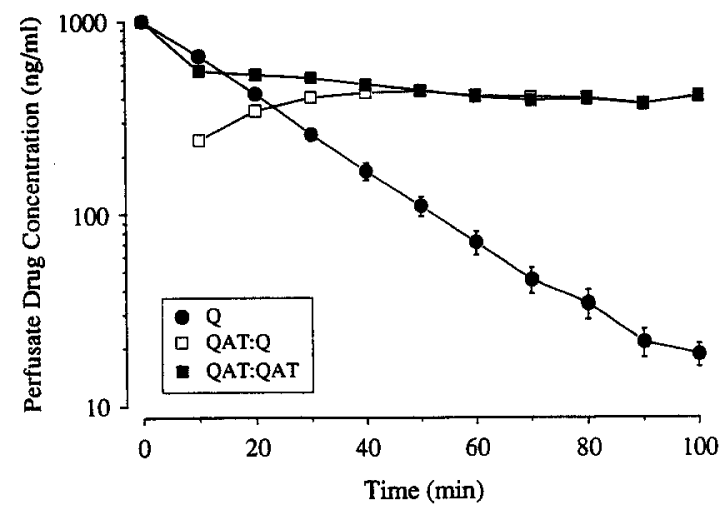

Fig. 4 Perfusate concentration-time curves for quinapril (Q) and quinaprilat (QAT :Q) after administration of quinapril $(n=9)$, and for quinaprilat (QAT:QAT) after administration of quinaprilat $(n=7)$. Data are shown as mean ISEM (error bars may be hidden by the symbol). 


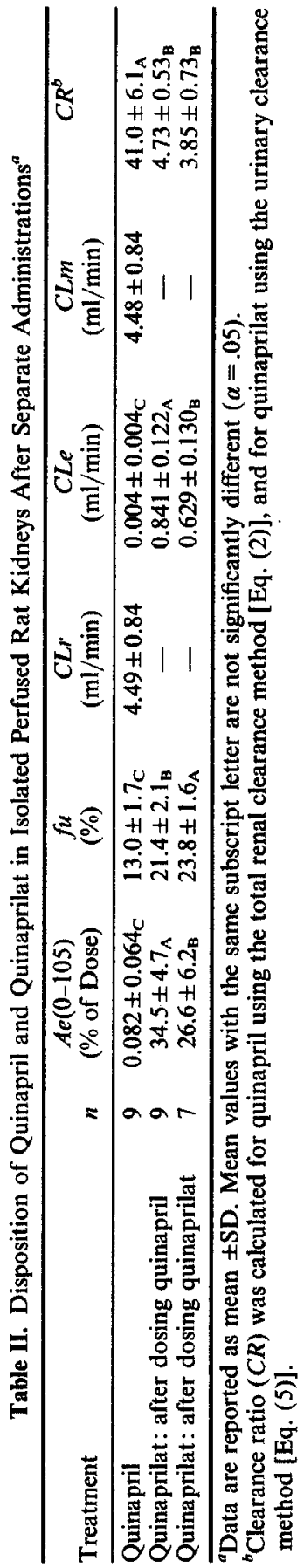




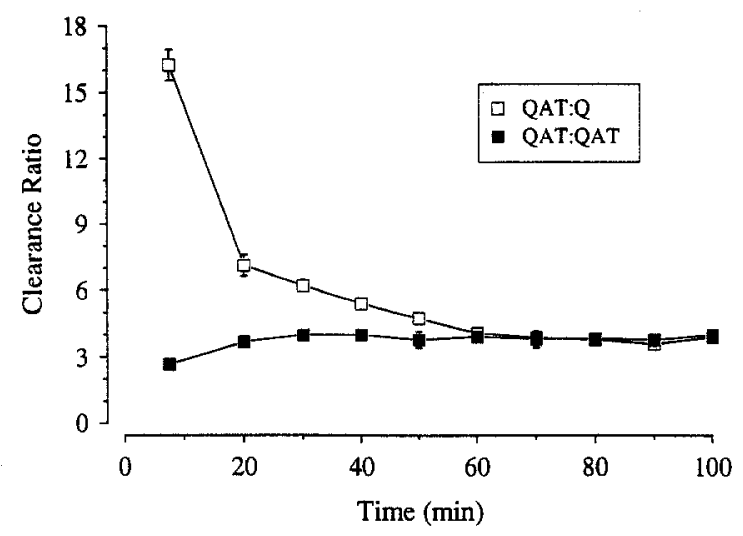

Fig. 5. Clearance ratio-time curves for quinaprilat (QAT:Q) after administration of quinapril $(n=9)$, and for quinaprilat (QAT : QAT) after administration of quinaprilat $(n=7)$. Data are shown as mean \pm SEM (error bars may be hidden by the symbol).

ratios of intrarenally formed and preformed quinaprilat are essentially the same by $\geq 60 \mathrm{~min}$ postdose. This finding indicates that once quinapril has been effectively removed from the system, the renal clearance of quinaprilat is the same regardless of its origin.

Although the fraction unbound for quinaprilat is statistically different following parent or metabolite dosing, this difference is small (about $10 \%$ ), and does not appear to reflect a competitive interaction between drug species. Overall, the fraction unbound was $20-25 \%$ for quinaprilat, and binding was linear over the narrow range of metabolite concentrations observed.

In contrast to quinapril excretion, about $25-35 \%$ of quinaprilat was recovered in the urine unchanged. It should be appreciated that after quinaprilat dosing, the urinary clearance and total renal clearance of quinaprilat are equivalent since the preformed metabolite is eliminated by renal excretion only (i.e., no metabolism occurs). However, the urinary clearance of quinaprilat (after quinapril dosing) reflects the contributions of quinaprilat's renal excretion from the recirculating perfusate and that which is formed from quinapril in the renal tubular cells.

\section{DISCUSSION}

In determining the net renal transport mechanism of a drug, it is implicitly assumed that metabolism by the kidney does not occur. Under this assumption, the renal clearance of a compound is accounted for by the 
individual contributions of glomerular filtration, secretion, and reabsorption processes. Intrarenal metabolism usually occurs within the tubular cells and, as a result, the amount of unchanged drug leaving the proximal tubular cell across the brush border membrane is considerably less than what was presented at the basolateral membrane. It is also possible that intrarenal metabolism may occur at sites distal to secretion as well as at luminal membrane surfaces. In each case, renal drug metabolism would substantially reduce the urinary recovery of intact drug, thereby, masking the contribution of secretory transport mechanisms. In this regard, the clearance ratio of enalapril (using the urinary clearance method) was reported as 0.55 in the recirculating, constant pressure IPK model (15), suggesting net reabsorption. However, this conclusion is tenuous since the method of analysis did not account for the fact that over $90 \%$ of enalapril's total renal clearance is metabolic (i.e., intrarenal formation of enalaprilat). As an alternative method of analysis (17), we calculated the clearance ratio of enalapril (using the total renal clearance method) as 7.8 , a result indicative of significant renal tubular secretion. Therefore, it seems reasonable to speculate that, in fact, enalapril is highly secreted into the renal tubular cells of the kidney, but that this process is masked by its subsequent and substantial intrarenal metabolism.

In the present IPK study, a negligible amount of quinapril $(<0.1 \%)$ was excreted into the urine as unchanged drug, resulting in a urinary clearance of only $0.004 \mathrm{ml} / \mathrm{min}$. Using the urinary clearance method, the clearance ratio of quinapril was calculated as $\mathbf{0 . 0 3 2}$. Based on this information alone, one would conclude that quinapril was transported by the kidney via a net reabsorption process. However, this would be an incorrect interpretation because over $99 \%$ of quinapril's total renal clearance is reflected by intrarenal metabolism. In contrast, the clearance ratio of quinapril was calculated as 41.0 (using the total renal clearance method), a value indicative of substantial tubular secretion. This conclusion is supported by preliminary experiments in the IPK (29) where the renal transport of quinapril was inhibited in a dose-dependent manner by organic anions (e.g., probenecid, $p$ aminohippurate) but not by organic cations (e.g., tetraethylammonium, quinine). Thus, the IPK studies with quinapril agree with our previous theoretical analysis (17), suggesting that for drugs in which all of the elimination processes are renal (transport and metabolic), total renal clearance is a better predictor of secretory transport processes than is urinary drug clearance. The ability of renal metabolism to mask secretory transport was also reported by Acara et al. (30) in micropuncture studies with choline. In these studies, a net secretion of choline was not observed at low plasma concentrations $(<325 \mu \mathrm{M})$ because of extensive metabolism to betaine by the proximal tubular cell. However, when the plasma concentrations were increased (325- 
$1000 \mu \mathrm{M}$ ), intracellular metabolism of choline was largely saturated, and secretion of choline became apparent.

Despite a larger urinary clearance of generated quinaprilat as compared to the preformed metabolite, this difference was not significant once the clearance was normalized for GFR. Thus, the average clearance ratio of quinaprilat was approximately 4 , indicating a net secretory mechanism for its overall renal transport. However, it should be appreciated that while the clearance of preformed metabolite (i.e., after dosing quinaprilat) was reasonably constant over the experimental time frame of IPK experiments, the clearance of generated metabolite (i.e., after dosing quinapril) was variable and time-dependent. This variability is predicted by Eq. (3) since the excreted metabolite has two sources, namely, that formed intrarenally from quinapril and that from prior reabsorption of quinaprilat into the recirculating perfusate. In the early time periods, quinaprilat excretion is dominated by quinapril to quinaprilat conversion while the perfusate concentrations of quinaprilat are low. In the later time periods, quinaprilat excretion is dominated by urinary clearance of reabsorbed metabolites while the perfusate concentrations of quinaprilat have accumulated. Thus, the clearance ratio of quinaprilat after quinapril administration is initially large, followed by smaller values approaching an asymptote (see Fig. 5). Finally, the clearance ratios of intrarenally formed and preformed quinaprilat are essentially the same as the supply of quinapril in perfusate becomes exhausted. This finding is in close agreement with a study performed on enalapril and enalaprilat in the isolated red blood cell-perfused rat kidney (15).

In rat IPK experiments, it was observed that quinapril was not metabolized to any other drug species other than quinaprilat, and that after quinaprilat administration, no other metabolites were found. In this context, the metabolic profile of whole organ studies is consistent with results from in vitro (31) as well as in vivo (11) experiments in rats. A comparison of IPK studies with that of humans is more difficult since information on the intrarenal metabolism of ACE inhibitors is lacking. Notwithstanding this omission, it appears that both quinapril and quinaprilat are cleared by the human kidney through a net secretion process; in both instances, we estimated their urinary clearance ratios at $\geq 10(32)$.

In conclusion, the disposition of quinapril and quinaprilat were evaluated in an isolated perfused rat kidney model. Quinapril was found to be substantially transported into renal proximal cells, as evidenced by a total renal clearance ratio of 41.0 . Although the urinary clearance of quinapril was negligible, conversion to its active metabolite was rapid and essentially complete. Thus, it appears that quinapril is, for all practical purposes, exclusively metabolized by the kidney to quinaprilat, a process coupled to its active tubular secretion. After quinaprilat administration, the urinary clearance 
ratio of preformed metabolite was 3.85 , a vale representing net tubular secretion. In addition, there were distinct differences in the temporal aspects of urinary drug clearance for generated vs. preformed metabolite.

\section{REFERENCES}

1. E. A. DeFelice and J. B. Kostis. New ACE inhibitors. In J. B. Kostis and E. A. DeFelice (eds.), Angiotensin Converting Enzyme Inhibitors, Alan R. Liss, New York, 1987, pp. 213-261.

2. M. Burnier, B. Waeber, J. Nussberger, and H. R. Brunner. Comparative cardiovascular effects of drugs used for hypertension. Drugs 39(Suppl. 1):32-38 (1990).

3. J. C. Garrison and M. J. Peach. Renin and angiotensin. In A. G. Gilman, T. W. Rall, A. S. Nies, and P. Taylor (eds.), The Pharmacologic Basis of Therapeutics, 8th ed., Pergamon, New York, 1985, pp. 749-763.

4. J. B. Kostis, J. J. Raia, Jr., E. A. DeFelice, J. A. Barone, and R. G. Deeter. Comparative clinical pharmacology of ACE inhibitors. In J. B. Kostis and E. A. DeFelice (eds.), Angiotensin Converting Enzyme Inhibitors, Alan R. Liss, New York, 1987, pp. 19-54.

5. J. B. Kostis. Angiotensin-converting enzyme inhibitors: Emerging differences and new compounds. Am. J. Hypertens. 2:57-64 (1989).

6. J. J. Raia, Jr., J. A. Barone, W. G. Byerly, and C. R. Lacy. Angiotensin-converting enzyme inhibitors: A comparative review. Ann. Pharmacother. 24:506-525 (1990).

7. W. A. Schlueter and D. C. Batlle. Renal effects of antihypertensive drugs. Drugs 37:900925 (1989).

8. V. J. Dzau. Mechanism of action of angiotensin-converting enzyme (ACE) inhibitors in hypertension and heart failure. Drugs 39(Suppl. 2):11-16 (1990).

9. P. A. Todd and R. C. Heel. Enalapril: A review of its pharmacodynamic and pharmacokinetic properties, and therapeutic use in hypertension and congestive heart failure. Drugs 31:198-248 (1986).

10. A. N. Wadworth and R. N. Brogden. Quinapril: A review of its pharmacological properties, and therapeutic efficacy in cardiovascular disorders. Drugs 41:378-399 (1991).

11. H. R. Kaplan, D. G. Taylor, S. C. Olson, and L. K. Andrews. Quinapril: A preclinical review of the pharmacology, pharmacokinetics, and toxicology. Angiology 40:335-350 (1989).

12. D. J. Tocco, F. A. de Luna, A. E. W. Duncan, T. C. Vassil, and E. H. Ulm. The physiological disposition and metabolism of enalapril maleate in laboratory animals. Drug Metab. Dispos. 10:15-19 (1982).

13. T. Unger, B. Schüll, W. Rascher, R. E. Lang, and D. Ganten. Selective activation of the converting enzyme inhibitor MK 421 and comparison of its active diacid form with captopril in different tissues of the rat. Biochem. Pharmacol. 31:3063-3070 (1982).

14. M. L. Cohen, K. D. Kurz, and K. W. Schenck. Tissue angiotensin converting enzyme inhibition as an index of the disposition of enalapril (MK-421) and metabolite MK422. J. Pharmacol. Exp. Ther. 226:192-196 (1983).

15. I. A. M. de Lannoy, R. Nespeca, and K. S. Pang. Renal handling of enalapril and enalaprilat: Studies in the isolated red blood cell-perfused rat kidney. $J$. Pharmacol. Exp. Ther. 251:1211-1222 (1989).

16. I. A. M. de Lannoy and K. S. Pang. Combined recirculation of the rat liver and kidney: Studies with enalapril and enalaprilat. J. Pharmacokin. Biopharm. 21:423-456 (1993).

17. D. E. Smith and A. R. Kugler. Influence of intrarenal metabolism on the analysis of renal drug transport mechanisms. J. Pharm. Sci. 83:1519-1520 (1994).

18. F. H. Epstein, J. T. Brosnan, J. D. Tange, and B. D. Ross. Improved function with amino acids in the isolated perfused kidney. Am. J. Physiol. 243:F284-F292 (1982).

19. H. A. Krebs and K. Henseleit. Untersunchugen über die harnstoffbildung im tierkorper. Z. Physiol. Chem. 210:33-36 (1932). 
20. J. M. Nishiitsutsuji-Uwo, B. D. Ross, and H. A. Krebs. Metabolic activities of the isolated perfused rat kidney. Biochem. J. 103:852-862 (1967).

21. R. H. Bowman. The perfused rat kidney. Meth. Enzymol. 39:3-11 (1975).

22. A. R. Kugler, S. C. Olson, and D. E. Smith. Determination of quinapril and quinaprilat by high-performance liquid chromatography with radiochemical detection, coupled to liquid scintillation spectrometry. J. Chromatog. B 666:360-367 (1995).

23. B. D. Ross. The isolated perfused rat kidney. Clin. Sci. Mol. Med. 55:513-521 (1978).

24. T. Maack. Physiological evaluation of the isolated perfused rat kidney. Am. J. Physiol. 238:F71-F78 (1980).

25. I. Bekersky. Use of the isolated perfused kidney as a tool in drug disposition studies. Drug Metab. Rev. 14:931-960 (1983).

26. C.A. Rodriguez and D. E. Smith. Influence of the unbound concentration of cefonicid on its renal elimination in isolated perfused rat kidneys. Antimicrob. Agents Chemother. 35:2395-2400 (1991).

27. C. A. Rodriguez and D. E. Smith. Influence of angiotensin II-induced alterations in renal flow on excretion of cefonicid in isolated perfused rat kidneys. Antimicrob. Agents Chemother. 36:616-619 (1992).

28. D. E. Smith, S. Guillard, and C. A. Rodriguez. Effect of angiotensin II-induced changes in perfusion flow rate on chlorothiazide transport in the isolated perfused rat kidney.

J. Pharmacokin. Biopharm. 20:195-207 (1992).

29. A. R. Kugler, S. C. Olson, and D. E. Smith. Effect of competitive transport inhibitors on quinapril and quinaprilat disposition in the isolated perfused rat kidney. Pharm. Res. 10(Suppl.):S415 (1993).

30. M. Acara, F. Roch-Ramel, and B. Rennick. Bidirectional renal tubular transport of free choline: A micropuncture study. Am. J. Physiol. 236:F112-F118 (1979).

31. A. R. Kugler, S. C. Olson, and R. A. Jordan. In vitro quinapril metabolism in rat, dog, monkey, and human liver preparations. Pharm. Res. 8(Suppl.):S239 (1991).

32. S. C. Olson, A. M. Horvath, B. M. Michniewicz, A. J. Sedman, W. A. Colburn, and P. G. Welling. The clinical pharmacokinetics of quinapril. Angiology 40:351-359 (1989). 